Revista de la red interuniversitaria de estudios sobre las literaturas rioplatenses contemporáneas en Francia

$14 \mid 2016$

Levrero

\title{
La escritura telérgica
}

Luciana Martínez

(c) OpenEdition

Journals

Edición electrónica

URL: http://journals.openedition.org/lirico/2246

DOI: $10.4000 /$ lirico.2246

ISSN: 2262-8339

Editor

Réseau interuniversitaire d'étude des littératures contemporaines du Río de la Plata

Referencia electrónica

Luciana Martínez, «La escritura telérgica », Cuadernos LIRICO [En línea], 14 | 2016, Puesto en línea el

07 junio 2016, consultado el 03 mayo 2019. URL : http://journals.openedition.org/lirico/2246 ; DOI

10.4000/lirico.2246

Este documento fue generado automáticamente el 3 mayo 2019.

\section{(c) $(1) \Theta \Theta$}

Cuadernos LIRICO está distribuido bajo una Licencia Creative Commons Atribución-NoComercialSinDerivar 4.0 Internacional. 


\title{
La escritura telérgica
}

\author{
Luciana Martínez
}

\section{Lecturas, redes y sinapsis}

1 Hace un tiempo, releyendo la obra del autor uruguayo que nos convoca en este número, advertí con claridad un aspecto que creo haber siempre intuido vagamente -por afán lúdico al menos, espero se me conceda dejar de lado el anodino enfoque epistemológico constructivista que implicaría sugerir de algún modo que toda crítica construye el objeto, y en cambio presuponer un ciertamente más estimulante misterio hermenéutico, cuyo desocultamiento nos entretendría infinitamente más a todos. Por aquél entonces, mes de mayo de 2014, quiso el azar que me encontrara simultáneamente revisando (con excusa de mi labor docente) las lecturas históricas de la figura de Hamlet. Las más sugerentes a mi entender -Coleridge, Mallarmé, Laforgue, Eliot- hicieron precipitar nuevas redes sinápticas.

2 «Coleridge hace de Hamlet un Coleridge », diría Eliot ${ }^{1}$; en efecto, una figura cuyo anhelo voraz de disolución de la carne en lo Absoluto no puede sino convertirlo en un ser romántico, dubitativo y melancólico, alma que se pasea inoperante por los salones del castillo, sumido en pensamientos y fantasías que adquieren una entidad desproporcionada en relación con los hechos externos -si acaso los hubiere... Y es que Hamlet, dice Coleridge, se halla en una especie de estado hipnótico, que necesariamente conduce a un desequilibrio de sus facultades sensitivas, por el que adquiere primacía lo imaginario $^{2}$. Por extemporáneo que suene, Agamben le da perfecta forma teórica a esta sensibilidad romántico decadente cuando en referencia a la melancolía dice que ésta, en su intento por dar corporeidad a un objeto de amor ausente, construye un universo fantasmático en el que la realidad exterior se torna irreal : la realidad física se vuelve incorpórea al tiempo que el universo fantasmal adquiere corporeidad. Dar forma o cuerpo al discurso paterno que se revela desde el plano fantasmático desata, de hecho, el inicio del drama en Hamlet, en tanto implica un desequilibrio -ya Agamben había afirmado que en la operación del melancólico existe siempre un « riesgo psíquico » ${ }^{3}-$ que familiariza al 
protagonista con la locura : la corporización de eso suprasensible se paga con una pérdida de "sustancia" del yo que, volátil, adquiere inusitados devenires.

De este punto en la cadena de lectura parte Mallarmé cuando dice que Hamlet es «un señor latente que no puede llegar a ser", que deambula en su laberinto de inquietud acompañado por lo que no son más que sombras que cifran las modulaciones en las que su indefinición podría llegar a devenir. Figura límbica, "detenido adolescente», dice Mallarmé, Hamlet no está sino esencialmente solo en el escenario de la obra; el resto de los personajes conforman una comparsa de fantasmas que Hamlet melancólicamente conjura a fuerza de injurias y golpes de espada ${ }^{4}$. En especial continuidad, Mallarmé actualiza la lectura romántica de Hamlet proponiendo como dilema central la búsqueda de una identidad tan cercana a la libertad indefinida de lo Absoluto (anhelo del origen ideal romántico) que rechaza cualquier devenir de maduración. Laforgue completará luego el cuadro cuando haga de Hamlet un torcido decadentista, cuya melancólica búsqueda subjetiva lo convierte en un clown que se recorta sobre un paisaje pantanoso y pestilente, imagen que no hace sino volver lo Absoluto una ciénaga mortuoria e informe que aloja como una matriz a personajes que están siempre a medio nacer, que nunca se despegan totalmente de ella ${ }^{5}$.

Por extraño que resulte, tiene cierta lógica que las interpretaciones románticas de la figura de Hamlet detonen ideas en torno a Levrero, cuyo anhelo de Absoluto se traduce en las diversas etapas de su obra como la búsqueda del Espíritu o de un Eterno Femenino, que se encarna en ocasiones en figuras informes y monstruosas; pero también en la búsqueda de la Literatura (con mayúscula, ideal de pura invención hacia el que la literatura no puede acercarse sino por contrapartida persiguiendo un grado cero en el que toca el dibujo y en el que la escritura se convierte en mero ejercicio caligráfico o relato de lo trivial) y en la del Yo ideal. ${ }^{6}$

Claro que todo este abanico de protoproblemas contempla diversas modulaciones en la obra del autor uruguayo. Tan diferentes parecen, que suele hablarse de dos etapas de su narrativa bien diferenciadas a partir de "Diario de un canalla"; y hasta incluso de dos tipos de lector de su obra (tan enfrentados como hinchadas en un clásico). De alguna manera, ese grupo conformado por "Diario de un canalla", El discurso vacío y La novela luminosa (confieso no creer en primera instancia que valga la pena incluir "Burdeos"), en clave simple y autobiográfica, gira en torno a un intento de volver la escritura una mancia ; tal como Levrero describe el concepto en su Manual de parapsicología : un ejercicio que distrae del objetivo ulterior y permite inducir el trance necesario para que suceda el advenimiento del Espíritu en la (y como) expresión sensible del relato. ${ }^{7}$ Así entendida, la literatura para Levrero se filia con la inquietud gnoseológica que es propia del romanticismo. Esa forma de autoconocimiento que es la literatura para Levrero conlleva, como para los románticos, la persecución de un inefable místico cuyo encuentro supondría al mismo tiempo el contacto con un yo primigenio ideal, yo como puro dibujo caligráfico vacío (o, por el contrario, completamente lleno) de semántica.

6 La literatura toca entonces la ciencia en esa búsqueda, juega a ser una forma de conocimiento supremo del yo ; búsqueda para la que la ficción es el mejor instrumento, tal como Levrero deja leer en "Apuntes de un voyeur melancólico". ${ }^{8}$ Ese juego esencialmente romántico en el que la literatura se convierte en ciencia de lo inasible se completa asimismo con un intento por hacer coincidir paradigmas. Los fenómenos del mundo se observan de cerca y, el resultado, se completa con el saber de la literatura, la cual no hace sino ampliar sus horizontes. Tal concepción, que responde al viejo 
imperativo de la Naturphilosophie schelliniana, es lo que hace que el conocimiento de la literatura se conecte siempre con los conceptos del Manual de parapsicología, los cuales aparecen a lo largo de toda la obra de Lervero. ${ }^{9}$

7 La literatura como mancia, como decía, ejercicio escritural que permite invocar al Espíritu ya que induce al trance y a la psicobulia (todos conceptos del Manual), parecería proponer la persecución, en cierta forma regresiva, de un Grado Cero en el que se encontraría al yo ideal (que Levrero llama "real", en oposición al yo activo de la vida diaria) en contacto con el Espíritu. Extremo opuesto a la invención libre y de proliferación entrópica (que el personaje Levrero de las ficciones confesionales afirma añorar), esta etapa se caracteriza por una impronta autobiográfica y despojada en la que pareciera que el yo de la vida cotidiana apuntara a reducirse a su mínima expresión, en un gesto esencialmente místico de desapego o vaciamiento del yo activo. ${ }^{10} \mathrm{El}$ personaje Levrero y el problema de la búsqueda de su yo "real" son por ende el centro gravitacional a partir del cual el resto de los personajes (por cierto un tanto carentes de profundidad) se mueven. ${ }^{11}$ Cual el Hamlet romántico, el personaje Levrero está solo en el escenario de las ficciones, y su drama central se encuentra indisociablemente ligado al problema de la búsqueda mística del yo : del aplomo justo del yo.

Ahora bien, es cierto: esto podría adjudicarse a las particularidades de las escrituras autobiográfica, confesionales, o como quiera llamárselas. No obstante, si se presta atención a la obra temprana del autor uruguayo es posible vislumbrar que ésta gira en torno a los mismos problemas. Un personaje masculino que deambula solo, librado al extravío en espacios que se bifurcan formando laberintos, se mueve en búsqueda de un inasible que toma fugazmente diferentes formas que sin embargo no lo representan (no podrían, dado que de más está decir que lo inasible es siempre irrepresentable). Singularidades femeninas encarnan parcialmente aquél Eterno Femenino que cifra el origen primigenio, figuras casi monstruosas en constante devenir, son acompañadas con frecuencia por dobles del propio protagonista que, tras la lectura de la obra tardía levreriana, resulta difícil no relacionar con el melancólico personaje Levrero, quien pone en términos conceptuales -diría que hasta precisos- las claves sobre las que ya versa, aunque solapadamente, el universo ficcional temprano. ${ }^{12}$

9 Mucho de Levrero podría analizarse en torno a esta propuesta, que se perfila casi naturalmente adecuada para pensar los textos que componen, por ejemplo, la Trilogía involuntaria (La ciudad, París, El lugar) o Desplazamientos. No obstante, es en otros relatos donde existen ciertas marcas específicas que permiten leer con precisión la naturaleza de este universo fantasmático que rodea al personaje Levrero, ya presente en las primeras ficciones. Adelantemos, que si en la obra tardía levreriana la literatura funciona como una mancia, en su obra temprana la escritura se mueve por una motivación telérgica. En esta diferencia radica la percepción de los dos momentos delimitados en la obra del autor : ahí donde en la escritura como mancia prima el gesto místico de reducción del yo, la escritura telérgica propone un proliferar constante que alimenta un devenir entrópico. La resolución del problema de la (aparente) partición de la obra de Levrero yace en visualizar que todas sus inflexiones gravitan en torno a la pregunta por la identidad. Se trata de encontrar el yo "real", ya sea por reducción de los rasgos que lo exceden (escritura como mancia) o por duplicación constante y entrópica de sus distintas versiones (escritura telérgica).

10 ¿Pero por qué adjudicar a esta modulación de la narrativa levreriana el calificativo que deriva del concepto de "telergía"?; o incluso antes, ¿qué significa este concepto, 
"telergía", que sin duda no va de suyo ? Algo hay de falaz en los personajes levrerianos; cuestión que incluso algunos textos, como "Alice Springs (El Circo, el Demonio, las mujeres y yo)" desocultan naturalmente al apelar a recursos temáticos hiperbólicos. Todo lo que sucede en el escenario de estos relatos tempranos, todos los personajes que funcionan como graciosos partenaires del protagonista no son más que puras proyecciones de una interioridad única en el relato; como si el universo levreriano se proyectara desde el interior de un único personaje, fuese producto de una pura interioridad que desborda hacia fuera creando laberintos. Pero en Levrero (y tal vez esto sea adjudicable a su impronta romántica, por la que la literatura siempre se concibe en relación con una pulsión científica; tal vez a su irreconocida relación con la ciencia ficción, cuyo irreprimible motor es la ficcionalización de paradigmas) este fenómeno encuentra una explicación en el universo propio del Manual de parapsicología, como ocurre con el concepto de mancia. Existe un fenómeno especial que sucede, como toda experiencia parapsicológica, cuando el sujeto « dotado » se encuentra en trance, el cual es asimismo dirigido por la psicoabulia (o en este caso « telebulia »), es decir, por la voluntad inconsciente o -más precisamente aun- del Inconsciente. Se trata de un proceso que, por « condensación » o « ideoplastía », desata fenómenos en el mundo físico en los que la psico o telebulia se materializa como sustancia ectoplasmática, toma la forma de objetos y de seres vivos en apariencia autónomos... a esta manifestación del inconsciente Levrero la llama « telergía »..$^{13}$

\section{Grado Cero y telergía}

11 La búsqueda de esa especie de Grado Cero de la Literatura en la escritura como mancia tiene en la obra temprana de Levrero una representación temática. Existe un grupo de textos con ciertas particularidades en los que impera una búsqueda de un lenguaje que trascienda el literario ; o más bien que amplíe sus posibilidades representativas. Se trata de textos en los que la búsqueda de la simpleza se traduce como anhelo de una literatura hermanada con el despojamiento retórico, con el minimalismo formal del lenguaje científico. Búsqueda melancólica de un lenguaje puro, neutro, básico, que persigue un Absoluto en diferentes formas : en la "Novela geométrica" es el lenguaje de la geometría el que teje la atmósfera, con el que se representa un intento de vuelta a un espacio plano que se entiende como primigenio (desligado del caos tridimensional de la cuidad) en que el personaje busca acercarse nuevamente, recuperar un Eterno Femenino encarnado en la figura dantesca de Beatriz; en Ya que estamos es el lenguaje del tratado de lógica con el que la literatura juega a decodificar el patrón esencial que regularía todo el universo, el cual se lee en términos de tensión entre la búsqueda de un Cero Absoluto como instancia ideal de reposo y la de un equilibrio energético (también ideal) de los elementos que componen el devenir caótico de la ciudad; finalmente, en ese extrañísimo texto que es "Tres aproximaciones ligeramente erróneas al problema de la Nueva Lógica", la vuelta a una retórica que imita la del tratado de lógica parecería encargarse de las implicancias de todo acto escritural. Con connotaciones muy similares a las de la patafísica de Alfred Jarry ( "la ciencia de las soluciones imaginarias»), la escritura como acto creativo es una «ciencia " que representa la única posibilidad de «fecundar ese óvulo monstruoso, primitivo, originario, el punto cero de todas las cosas, creador de los campos magnéticos, de la ilusión de la carne... $»^{14}$. La literatura como Nueva Lógica es una forma de devenir en lo real (y de devenir de lo "real"), por vía humorística, que sólo halla una definición en la 
siempre renovada autodefinición de su praxis singular. La práctica escritural proliferante constituye una presentación de ese Absoluto por vejación : las ficciones son la forma en la que éste se presenta en sus múltiples expresiones bastardas. A eso parecería arribar la Nueva Lógica. ${ }^{15}$

Dicha serie, cuyo análisis merecerá sin duda un texto aparte, encierra un movimiento regresivo, romántico, de búsqueda de un espacio y una escritura blanca que se acerque a un Absoluto entendido como origen inasible. No sería desatinado incluso pensar que la preocupación que subyace aquí tendrá por modulación tardía la escritura como mancia. Por contrapartida, se encuentran aquellos textos que se mueven por la búsqueda de la habilitación de un afuera que, no obstante, siempre se resuelve de forma fallida, en tanto todo termina reducido a una interioridad que se exuda en forma de laberintos oníricos. $\mathrm{Si}$ en las ficciones de "Grado Cero" el protagonista-narrador se encuentra solo, aislado en una especie de espacio aséptico que propicia la especulación en torno a una idealidad abstracta, aquellos relatos en los que prima una pulsión de habilitación de un afuera se plagan de distintos personajes que se proponen en ocasiones (fundamentalmente en la Trilogía involuntaria) como « puntos de referencia » en el devenir errático y extravíado que toma la indagación siempre central del protagonista en torno a la identidad ${ }^{16}$.

Como si salir de ese espacio ideal significara la necesidad de mantener ciertos puntos de referencia, cual migajas del camino, los personajes parecieran encarnar por momentos una posibilidad (ilusoria) de eventual retorno, ahí cuando en el "afuera" la pregunta por la identidad se multiplica laberínticamente. El problema radica en que los puntos de referencia terminan siendo "telarañas », relaciones que obturan el libre deambular del protagonista por los infinitos pasajes en busca de su identidad ideal ${ }^{17}$. El personaje Levrero termina entonces siempre preso de una encrucijada que lo confina a un limbo intersticial : el movimiento regresivo hacia lo Absoluto constituye una tentación a evitar por su imposibilidad (y por el gasto energético que implica para el yo de la vigilia, como afirma el personaje Levrero en las ficciones autobiográficas), el movimiento libre de proyección incesante de un "afuera" parece conllevar el riesgo del extravío, pérdida de vista de ese amado origen primigenio, y el detenimiento en los puntos de referencia (relación estable con los distintos personajes que aparecen) lo que obstaculiza la búsqueda de la identidad ideal.

Si pudiera hacerse una "reducción" de los problemas en Levrero, si acaso se me permite el lenguaje de las ciencias formales que le fue tan caro al autor, diría que una vez más todo es en definitiva una cuestión de equilibrio : se trata de encontrar un "punto óptimo » entre la necesidad de exploración libre de la interioridad del yo (que toma la forma, falaz, de una errancia por un afuera laberíntico) y el anclaje en los puntos de referencia. ${ }^{18}$ Como es habitual en Levrero, este problema toma perfecta forma teórica en una de las ficciones de "Grado Cero" antes mencionadas. La Nueva Lógica (que no es más, en definitiva, que la escritura ficcional) representa justamente un «movimiento fóbico pendular » que oscila entre la «agorafobia », miedo a lo abierto, y la «claustrofobia», cuya definición en Levrero debería ajustarse, pasar a definir un tipo de miedo particular a que los vínculos signifiquen una definición permanente del yo en alguna de sus modulaciones (se trata de la identidad como trampa ${ }^{19}$.

Ahora bien, culminada la necesaria digresión, me interesa señalar que dentro de estas ficciones en donde prima la aparición de una batería de personajes y escenarios, se encuentra un grupo especialmente marcado por el problema del doble. El sujeto mismo es 
un infinito de posibilidades, le explica de forma prístina uno de los personajes al protagonista de Dejen todo en mis manos,

-Acuérdese, joven: hay dos infinitos (...); infinito muy grande, infinito muy pequeño ; y dentro suyo, otros infinitos. Cada átomo cuerpo, pequeño planeta. No desalentar las cosas que pasan; vida continúa. Vida igual a mosquita curiosa, revolotea todos lados y mete nariz en todo. A veces mosquita cae en telaraña. Eso bueno. Naturaleza. Ley. No bueno caer telaraña propia. ${ }^{20}$

no obstante habitar el mundo significa tejer(se) uno mismo, y dejarse tejer por los propios mitos y relatos que ha creado ; también se le advierte eso al protagonista. En ese proceso, lo amenazante parece radicar en quedar atrapado en las telarañas. Ahí cuando el espacio y los «puntos de referencia» se tornan estables y el laberinto infinito comienza a desentrañarse, aparece la trampa. Es la trampa de la identidad, la identidad como trampa en el sentido opuesto a la identidad ideal : la fijación del propio sentido como recorte y no como totalidad ideal del yo. La percepción de la trampa no es sino el momento en el que el movimiento pendular levreriano se inclina en favor de la "claustrofobia ", tal como se lo representa en "Tres aproximaciones...", y eyecta al protagonista hacia la exploración de un afuera que precariamente se reduce a la reproducción de un infinito interior : el afuera es, sino falacia, al menos un movimiento fallido en el que todo termina reducido al mundillo del yo y sus dobles (tal vez por « agorafobia »).

En el universo levreriano no podría ser de otra manera. Si se quiere, la matriz del problema se prefigura en "Precaución"; no por nada, texto cuya retórica permitiría incluirlo en la serie de "Grado Cero". En sí mismo el sujeto no es sino un compuesto casi infinito de "homúculos" que conviven; y si pareciera a veces que existe en nosotros varias vidas paralelas o simultáneas es porque en nuestra mente habitan "quistes psíquicos » o "teratomas » siempre pujando por su autonomía. "Supongamos que un cirujano logra extraer vivo al hermano enquistado...», a este mellizo monstruoso (recordemos la etimología del afijo "tera- ", nos advierte la voz del relato) que nos compone $^{21}$ : gran parte de la narrativa levreriana ronda en torno a ese desafío que aparece en "Precaución", como si la ficción permitiera observar y por momentos conjurar todas las partes agregadas del yo a través de una operación telérgica. Expulsando los quistes de sí, el yo ideal es perseguido, en un movimiento que los transforma en fantasmas ectoplasmáticos, que quedan flotando en ese pantano onírico que envuelve los relatos.

Pero una vez el enredo armado, el protagonista emprende la retirada y abandona el escenario para partir hacia otro lares. $Y$ es que la pregunta por la identidad ideal del yo implica un constante desdoblamiento que no puede sino permanecer irresuelto y embrollado. Porque si en las ficciones de Grado Cero existe una búsqueda regresiva de un Absoluto, en las ficciones telérgicas en las que se proyecta un falaz afuera se intenta encontrar el yo en el hacer proliferante de sus infinitas versiones : en el hacer infinito de la Bildung (formación) subjetiva, que siempre contempla un sujeto como Sistema o totalidad orgánica en constante autoformación que se conoce a sí mismo (según la impronta del concepto schelliniano de naturaleza) presentándose u objetivándose en múltiples versiones. Vuelta regresiva o pretendido movimiento hacia el afuera, en ambas inflexiones el relato oficia como un laboratorio en el que la exploración escritural de las posibilidades del yo es atravesada por una metodología concebidamente humorística : de nuevo, o fingida inocencia romántica cuyo fin ulterior es el Absoluto siempre inasible, o (en el caso de las ficciones telérgicas que nos atañen) disparatadas hipérboles, fábulas que son la condición de posibilidad de presentación por la vía ficcional de las infinitas, 
atrofiadas y fantasmales versiones del yo. El problema del conocimiento del yo se abre en esas dos modulaciones.

Bien podría ahondarse en este problema analizando las proyecciones etcoplasmáticas del yo que pueblan "Alice Springs (El Circo, el Demonio, las mujeres y yo)", las cuales conforman un simulacro de realidad en el que está presente la pregunta por lo real en todas sus formas; o en el mismo Nick Carter se divierte mientras el lector es asesinado y yo agonizo, en el que los enredos del protagonista y sus dobles parodian hacia el final la forma melodrama. Como si en este texto la pregunta insistente de la narrativa levreriana en torno al yo no pudiera sino decantar en un reconocimiento sobre lo disparatado en la formulación del problema, el enigma de Nick Carter se vuelve hacia el final un develamiento propio de la telenovela en la que los devenires del yo se radicalizan: los dobles, Watson y Tinker, carecen de antropomorfismo, al tiempo que la figura del Eterno Femenino se encuentra encarnada por una Araña que teje el enredo, cual telaraña, en la que el detective corre el riesgo de terminar atrapado.

La relación sexual con esa forma hipergrotesca que es la Araña (al igual que con la Beatriz de la "Novela geométrica"), cifra la necesidad de "fecundación de ese óvulo monstruoso", como se formula en "Tres aproximaciones..." : se trata de una representación del contacto con el Eterno Femenino (inflexión de ese Absoluto que en la obra tardía tomará la forma de la búsqueda del Espíritu, la Literatura, el Inconsciente) como única vía de acercamiento al yo ideal. Por eso precisamente la fecundación de la Araña genera los dobles (más que nunca aquí monstruosos, hijos de Nick Carter y la Araña) que pueblan el texto y desatan una ficción en la que el policial se desquicia y se transforma en incestuoso melodrama : los personajes son al mismo tiempo dobles y vástagos, al igual que el afuera no es más que interioridad reproducida ; y la ficción copia bastarda en la que lo Absoluto se presenta. La cadena de desplazamientos del enigma de la identidad ideal, cuyo develamiento persigue la ficción, hace aun más certera la futilidad de la empresa gnoseológica romántica, de la que el humor melodramático no es más que una inevitable consecuencia. En ese contexto, los personajes, manifestaciones del único personaje, digamos "con espesor", que siempre se encuentra obsesionado con el mismo problema, no son más que un motor exploratorio, son la razón de posibilidad de ese detective del enigma de la identidad que es Nick Carter :22

¡Ah, Carter! Allá vas diciéndote : 'Aquí viene Nick Carter, el detective más famoso del mundo, a resolver un enigma.' Pero en el fondo de tu almita sabes que no es cierto. El enigma eres tú, Nick Carter, el único enigma verdadero que nunca has podido resolver, el enigma de tu vida vacía, de tu verdadera identidad (...) ¿cuántos placeres simples de la vida has dejado de lado por tu espantoso narcisismo ? Sube al tren, Nick Carter, a ese tren que te llevará al Castillo en pos de una nueva victoria artificial. Llevas al asesino en tu bolso de mano, Nick Carter. Lo has llevado siempre. (...)

Y tú, lector, que te apiadas del vacío de Nick Carter, ¿qué me puedes decir de ti mismo ? De tu enigma, de tu identidad. ¿No te has dado cuenta de que también a ti te han asesinado? A ti también te han clavado un cuchillo en la espalda el día mismo en que naciste. Pero en tu ceguera le llamas vida a tu vida, a eso que arrastras, como tantos lectores, infectando el mundo. Todavía no ha nacido el detective que investigue tu muerte, lector. Nunca serás vengado, anónimo gusano. No eres mejor que Nick Carter, ni que yo. ${ }^{23}$

21 Helo aquí, en Nick Carter se divierte mientras el lector es asesinado y yo agonizo, el anónimo gusano, la larva amorfa que cifra al sujeto ideal que nunca podrá emerger, potencialidad abortada sobre la que el personaje Levrero tercamente, melancólicamente, insiste; helo 
aquí, cual el gusano de El innombrable de Beckett, esa identidad llamada « Worm » que la voz narrativa afirma que está detenida en sus orígenes, venida al mundo sin nacer. El asesino es sin duda el doble, cuerpo en el que uno de los fantasmas neuróticos (« quistes psíquicos») que habitan inacabados en el sujeto desarrolla su forma y adquiere autonomía: en el caso de Nick Carter, ese personaje extraño en los límites de la animalidad, doble e hijo del protagonista, inseparable compañero y enemigo oculto, llamado Watson/Tinker.

La concepción del doble, enemigo (y a la vez versión parcial) de ese yo ideal irrecuperable, es aún más clara a mi entender en un texto como Fauna; en donde incluso se repone e ilustra la definición de telergía para explicar los diversos fenómenos que suceden en el relato, entre ellos, las diversas manifestaciones de las personalidades femeninas como parte del mismo inconsciente de una única protagonista que proyecta distintas versiones «a medio terminar » o «atrofiadas» de $\mathbf{~} \mathbf{1}^{24}$. Por eso, la tarea del parapsicólogo (que bien podríamos relacionar con esa figura que denomino el "personaje Levrero") es hacer devenir el yo «real» de la mujer, descartando las diferentes « copias defectuosas » que desde ella parecen proyectarse y que él capta en estado de trance ${ }^{25}$. Aquí también el corazón del relato encierra el enigma de la identidad del yo "real", como lo llama Levrero en las ficciones autobiográficas; enigma hacia el que el parapsicólogo-detective se encamina ${ }^{26}$. Al igual que Nick Carter, Fauna se construye como un policial -policial parapsicológico, diría, en este caso- en el que el develamiento de la identidad adquiere los tintes de un melodrama familiar: los desdoblamientos de la figura femenina deben rastrearse en los traumas de una madre sobreprotectora (que la retienen en el espacio íntimo y cerrado de su infantilidad) y un padre ausente (que imposibilita la salida a un afuera); aspectos ambos que se refieren en varios de los textos de Levrero como autobiográficos. En este contexto, la imposibilidad de emergencia del verdadero yo parecería implicar la proyección de dobles, siempre inacabados, y el deambular límbico de los protagonistas que se pasean por escenarios a mitad de camino entre la vigilia y el sueño.

Se trata en definitiva de un proceso esencialmente melancólico, en el que el yo se detiene, límbico, en múltiples latencias; sin terminar de asumir ninguna de sus versiones, las perpetúa como fantasmas (realizadores insoslayables de la ficción) al tiempo que las combate por ser obstáculo hacia el yo ideal y su relación con las distintas inflexiones de lo Absoluto. En esa telaraña se pierden los personajes levrerianos, tensionados por hilos que ellos mismos construyen, deciden súbitamente abandonar con lo puesto la escena, cuyos conflictos, de más está decir, permanecen irresueltos. Algo de esto recuerda el mencionado ensayo en el que T.S. Eliot califica a Hamlet como una obra fallida, en la que la emoción profunda del Príncipe de Dinamarca (según Eliot, sentimiento de repugnancia de un hijo hacia su madre culpable) no encuentra, por excesiva, un " correlato objetivo » adecuado en la obra. De más está decir que esta propuesta sin duda se enmarca en las particularidades del ensayo de autor. No obstante, algo en la dilación hamletiana, que bien interpretaron tempranamente las lecturas románticas, necesariamente debe terminar en irresuelto y fallido.

Al igual en Levrero, la adecuada resolución de ese universo que se dilata y prolifera, por momentos sin rumbo, no podría llegar en ningún caso. La persecución de la identidad ideal excede cualquier escenario literario que se construya para su presentación, y no puede sino significar una empresa fútil en la que el personaje Levrero termina reducido a 
un clown melancólico: ninguno de sus personajes puede ser un adecuado correlato objetivo para la presentación de ese Absoluto que es el yo ideal.

Si la búsqueda del eje de la identidad, del aplomo justo del yo por medio de la caligrafía es imposible (al igual que lo es el acceso a las formas de lo Absoluto), también lo es su encuentro en las distintas versiones que proporcionan las operaciones telérgicas. Aunque en este último caso la paradoja humorística levreriana radica en que la escritura telérgica constituye, de alguna manera, la posibilidad más cercana al yo como totalidad. Precisamente la presentación humorística de la suma de todas las fantasmales, neuróticas versiones que lo conforman, da corporeidad a ese Absoluto de la única manera posible. El personaje Levrero tendrá que conformarse con eso. Entonces, por operación telérgica el yo proyecta algo desde sí, los fantasmas adquieren corporeidad en un anhelo de presentación de ese Absoluto... y se hace la luz : aparecen los personajes en el universo levreriano.

\section{BIBLIOGRAFÍA}

\section{BIBLIOGRAFÍA}

Agamben, Giorgio. Estancias (La palabra y el fantasma en la cultura occidental). Madrid : Editora

Nacional, 2002.

Arnaldo, Javier (comp.). Fragmentos para una teoría romántica del arte. Madrid : Tecnos, 1987.

Barthes, Roland. El grado cero de la escritura (seguido de Nuevos ensayos críticos). Buenos Aires : Siglo XXI, 2006.

Coleridge, Samuel. "Estudios sobre Hamlet”. Henríquez Ureña, Pedro (comp.), Hamlet (en sus tres versiones). Buenos Aires : Losada, 1940.

Corbellini, Helena. "Post-facio. Serie negra en patchwork". Levrero, Mario, Nick Carter se divierte mientras el lector es asesinado y yo agonizo. Montevideo : Arca, 1992.

D’Angelo, Paolo. La estética del Romanticismo (Trad. Juan Díaz de Atauri). Madrid : La balsa de la Meduza, 1999.

De Certeau, Michel. La fábula mística. Siglos XVI y XVII (Trad. J.L. Moctezuma). México : Universidad Iberoamericana, 1993.

De Rosso, Ezequiel. “Otra trilogía : las novelas policiales de Mario Levrero”. De Rosso, Ezequiel (selec.), La máquina de pensar en Mario. Ensayos sobre la obra de Levrero. Buenos Aires : Eterna Cadencia, 2013.

Eliot, T.S. "Hamlet", Los poetas metafísicos y otros ensayos sobre teatro y religión (Tomo I). Buenos Aires : Emecé, 1944.

Fuentes, Pablo. "Levrero : el relato asimétrico”. De Rosso, Ezequiel (selec.), La máquina de pensar en Mario. Ensayos sobre la obra de Levrero. Buenos Aires : Eterna Cadencia, 2013.

Givone, Sergio. "El giro místico" y "Romanticismo y nihilismo". Historia de la nada. Buenos Aires : Adriana Hidalgo, 2002. 
Gode Von Aesch, Alexander. El romanticismo alemán y las Ciencias Naturales. Buenos Aires : Espasa Calpe, 1947.

Kohan, Martín. “La idea misma de ciudad”. De Rosso, Ezequiel (selec.), La máquina de pensar en Mario. Ensayos sobre la obra de Levrero. Buenos Aires : Eterna Cadencia, 2013.

Lacoue-Labarthe, Philippe - Nancy, Jean-Luc. L'Absolu Littéraire. Théorie de la Littérature du Romantisme Allemand. Paris : Éditions du Seuil, 1978.

Laforgue, Jules. "Hamlet o las consecuencias del amor filial", Moralidades legendarias. Madrid : Cátedra, 1994.

Levrero, Mario. “Alice Springs (El Circo, el Demonio, las mujeres y yo)”, Todo el tiempo. Montevideo : Ediciones de la Banda Oriental, 1982.

Levrero, Mario. “Apuntes de un voyeur melancólico”, Espacios libres. Buenos Aires : Puntosur, 1987.

Levrero, Mario. “Diario de un canalla”, El portero y el otro. Montevideo : Trilce, 1992.

Levrero, Mario. "Los laberintos”, Espacios libres. Buenos Aires : Puntosur, 1987.

Levrero, Mario. “Novela geométrica”, El portero y el otro. Montevideo : Arca, 1992.

Levrero, Mario. “Precaución”, El portero y el otro. Montevideo : Arca, 1992.

Levrero, Mario. “Tres aproximaciones ligeramente erróneas al problema de la nueva lógica”. Alicia Torres (selec.), Humor a la uruguaya : selección de cuentos, artículos y crónicas (1947-1997), Buenos Aires : Colihue, 1999.

Levrero, Mario. Dejen todo en mis manos. Buenos Aires : Mondadori, 2007.

Levrero, Mario. El discurso vacío. Buenos Aires : Interzona, 2006.

Levrero, Mario. El lugar. Barcelona : Mondadori, 2008.

Levrero, Mario. Fauna/Desplazamientos. Buenos Aires : Ediciones de la Flor, 1987.

Levrero, Mario. La ciudad. Barcelona : Mondadori, 2008.

Levrero, Mario. La novela luminosa. Barcelona : Mondadori, 2008.

Levrero, Mario. Manual de parapsicología. Buenos Aires : Los libros de El Péndulo, 1979.

Levrero, Mario. Nick Carter se divierte mientras el lector es asesinado y yo agonizo. Montevideo : Arca, 1992.

Levrero, Mario. París. Barcelona : Mondadori, 2008.

Levrero, Mario. Ya que estamos. Montevideo : Cauce, 2001.

Libera de, Alain. Eckhart, Suso, Tauler y la divinización del hombre (Trad. Manuel Serrat Crespo). Barcelona : José J. de Olañeta Editor, 1999.

Mallarmé, Stéphane. “Hamlet”. Henríquez Ureña, Pedro (comp.), Hamlet (en sus tres versiones). Buenos Aires : Losada, 1940.

Martinez, Luciana. “Levrero y una genealogía para otro realismo”. Contreras, Sandra (comp.), Cuadernos del seminario II : Realismos, cuestiones críticas. Rosario : UNR Editora, 2013.

Martinez, Luciana. "Mario Levrero, la ciencia y la literatura”. De Rosso, Ezequiel (selec.), La máquina de pensar en Mario. Ensayos sobre la obra de Levrero. Buenos Aires : Eterna Cadencia, 2013. 
Martinez, Luciana. "Mario Levrero : parapsicología, literatura y trance”. Giordano, Alberto (comp.), Cuadernos del seminario I: Los límites de la literatura. Rosario : UNR Editora, 2010.

Martinez, Luciana. "Una distancia óptima : mística, parapsicología y termodinámica en Levrero". Bartalini, Carolina (comp.), Coloquio Mario Levrero. Buenos Aires : UNTREF Editora (en prensa).

Safranski, Rüdiger. Romanticismo. Una odisea del espíritu alemán (Trad. Raúl Gabás Pallás).

Barcelona : Tusquets, 2009.

Schelling, F.W.J, Escritos sobre filosofía de la naturaleza. Madrid : Alianza, 1996.

Zolla, Elémire. Los místico de occidente I. Mundo antiguo pagano y cristiano (Trad. José Pedro Tosaus Abadía). Barcelona : Paidós, 2000.

\section{NOTAS}

1. T.S Eliot, "Hamlet", Los poetas metafísicos y otros ensayos sobre teatro y religión (Tomo I), Buenos Aires : Emecé, 1944, p. 179.

2. Samuel Coleridge, "Estudios sobre Hamlet". Henríquez Ureña, Pedro (comp.), Hamlet (en sus tres versiones). Buenos Aires : Losada, 1940, pp. 221-222.

3. Giorgio Agamben, Estancias (La palabra y el fantasma en la cultura occidental), Madrid: Editora Nacional, 2002, p. 50.

4. Stéphane Mallarmé, “Hamlet”, Henríquez Ureña, op. cit., pp. 225-226.

5. Jules Laforgue, "Hamlet o las consecuencias del amor filial", Moralidades legendarias, Madrid : Cátedra, 1994.

6. La búsqueda del Absoluto que en Levrero toma las diversas formas que recién mencionaba tiene las mismas connotaciones paradójicas que en el romanticismo. A lo que me refiero es a que, por ejemplo, la búsqueda del yo ideal (aquello que Levrero llama fundamentalmente en sus ficciones autobiográficas yo "real") es búsqueda de un no-yo; es decir: una instancia que se acerca tanto a la libertad informe e incondicionada de lo sublime kantiano (e incluso a la "cosa en sí") que es por definición contraria al yo subjetivo.

7. Hay que entender esta afirmación en relación con el Darstellung romántico (presentación o puesta-en-presencia). Se trata en definitiva del problema central del romanticismo alemán : la presentación finita de lo infinito, o la presentación sensible de lo Absoluto por vía ficcional.

8. El imperativo de presentación (Darstellung) del Absoluto implica necesariamente que un problema gnoseológico (e incluso epistemológico) recorre los cimientos del romanticismo alemán. Además, en la medida en que el romanticismo persigue la presentación sensible por medio del arte de algo suprasensible que siempre es inasible, ese problema de conocimiento presupone uno religioso. El primer costado de la ciencia romántica (en clara oposición al concepto que se está formando en la modernidad) implica un claro acercamiento a una dimensión místico religiosa por medios estéticos. De ahí el sincretismo entre arte, filosofía y ciencia en el conocido fragmento 115.

9. La segunda arista del problema de la ciencia romántica se relaciona directamente con la Filosofía de la Naturaleza de Schelling. Contrariamente a la idea de naturaleza como mecanismo que se instauró a partir de los principios empiristas newtonianos, Schelling recupera la idea de naturaleza como dinámica activa entre fuerzas de Kant (Principios metafísicos de la ciencia de la naturaleza, 1786) para formular una imagen de naturaleza orgánica en la línea del Timeo. La idea platoniana del "alma del mundo" presente en todos los sustratos permite relacionar para Schelling la dimensión trascendental con la sensible, e inversamente. La filosofía de la naturaleza será entonces una "física especulativa" que analice las fuerzas observables en el mundo natural 
(fuerzas de atracción y repulsión, por ejemplo, presentes en la electricidad, el magnetismo, los procesos químicos) para deducir de allí principios trascendentales que tendrían correspondencia. 10. Para ampliar sobre el desapego y la búsqueda del yo en las distintas corrientes de la mística consultar los textos de De Certeau, De Libera y Zolla, consignados en bibliografía.

11. Aunque en referencia a ciertos textos de la obra temprana, Ezequiel De Rosso señala (siguiendo a Pablo Fuentes) que los antagonistas en Levrero parecen existir sólo en función del personaje narrador y que carecen de psicologías complejas. De Rosso, Ezequiel. "Otra trilogía : las novelas policiales de Mario Levrero". De Rosso, Ezequiel (selec.), La máquina de pensar en Mario. Ensayos sobre la obra de Levrero, Buenos Aires : Eterna Cadencia, 2013, 146.

12. Habría que hacer la salvedad de que, aunque operativa, esta distinción entre la obra temprana y otra tardía de corte autobiográfico tiene sus matices. Un texto como Dejen todo en mis manos, por ejemplo, sin duda complica esta periodización, ya que cronológicamente se encuentra más cercano a la obra tardía, al tiempo que presenta problemas a partir de los cuales podría relacionárselo con textos previos.

13. Mario Levrero, Manual de parapsicología, Buenos Aires: Los libros de El Péndulo, 1979, pp. 51-55.

14. Mario Levrero, “Tres aproximaciones ligeramente erróneas al problema de la nueva lógica”. Alicia Torres (selec.), Humor a la uruguaya: selección de cuentos, artículos y crónicas (1947-1997), Buenos Aires : Colihue, 1999, 119.

15. En consonancia con el paradigma romántico, el humor (o también ironía romántica, en términos de Friedrich Schlegel) como vía paradójica del conocimiento imposible toma dos formas en Levrero: la de la pretendida inocencia que propone una vuelta al origen por despojamiento (literatura como mancia) y la de la fábula o Märchen, es decir, presentación (Darstellung) por la vía ficcional de lo Absoluto en sus múltiples posibilidades sensibles o finitas.

16. La mención a los puntos de referencia es una constante en la narrativa levreriana ; tanto en la Trilogía involuntaria, como en la "Novela geométrica", las referencias son explícitas : las figuras femeninas principalmente funcionan como ejes de estabilización. Esto es particularmente notorio en un texto como El Lugar, en el que la necesidad de referencia que se enuncia en los primeros párrafos se traduce en la necesidad de relación con los diferentes personajes, en especial con Alicia.

17. En el relato "Los laberintos", el protagonista elabora una teoría en donde se definen y analizan las interacciones de los conceptos de "telaraña", "laberinto" y "trampa" ; desarrollo que es muy iluminador para comprender cómo juegan en general estas ideas en la narrativa de Levrero.

18. En "Una distancia óptima : mística, parapsicología y termodinámica en Levrero" he analizado cómo el concepto de "punto óptimo", que Levrero propone en el Manual de parapsicología, se encuentra detrás de la propuesta de búsqueda de equilibrio en un texto como Ya que estamos.

19. Levrero, "Tres aproximaciones ligeramente erróneas al problema de la nueva lógica", op. cit., pp. 122-123. Habría que señalar además que Martín Kohan en "La idea misma de ciudad" hace un rastreo de los conceptos de "claustrofobia" y "agorafobia", que aparecen como marcas textuales en distintos textos del autor uruguayo, para analizar la experiencia de la ciudad a partir de una dinámica entre ambos.

20. Mario Levrero, Dejen todo en mis manos. Buenos Aires : Mondadori, 2007, p. 114.

21. Mario Levrero, "Precaución”, El portero y el otro. Montevideo : Arca, 1992, pp. 76-77.

22. En "Post-facio. Serie negra en patchwork", Helena Corbellini hace referencia por primera vez al problema de la identidad en relación con el doble en Nick Carter.

23. Mario Levrero, Nick Carter se divierte mientras el lector es asesinado y yo agonizo. Montevideo : Arca, 1992, pp. 55-56.

24. Levrero, Mario. Fauna. Aires : Ediciones de la Flor, 1987, pp. 89-90.

25. Levrero, Ibid., pp. 33. 
26. No se me pasa por alto que en Levrero la indagación central sobre la identidad conduce naturalmente en ocasiones a la retórica policial ; y de ahí que en este trabajo se hayan citado textos como Dejen todo en mis manos, Nick Carter y Fauna. Esta propuesta no puede sino confluir con la de Ezequiel de Rosso, especialista en el género, quien sostiene que la estructura de búsqueda levreriana supone necesariamente una afinidad entre su máquina narrativa y cierta matriz del policial, sólo que en Levrero habría una apertura del enigma y un fracaso en la clausura. De Rosso, op.cit., 154.

\section{RESÚMENES}

"La escritura telérgica" propone un análisis de la obra temprana de Levrero a partir del concepto de "telergía" que aparece en el Manual de parapsicología (1979). Si en trabajos anteriores se ha argumentado que la ficción levreriana tardía intenta cumplir una función de mancia (concepto también incluido en el Manual) para lograr acercamiento a un yo Ideal inasible y a diversas formas de lo Absoluto, aquí se propone que en los primeros textos del autor uruguayo la búsqueda de la identidad ideal se lleva a cabo a partir de la presentación de diferentes tipos de personajes que no son más que versiones incompletas o parciales del yo del protagonista. La telergía opera en este último sentido como un concepto que explica a partir del universo del Manual ciertas inflexiones singulares de su narrativa temprana, como las del doble. En relación con el problema de la identidad, central en Levrero, se analizan también otros conceptos que aparecen en sus ficciones, como "telaraña", "laberinto" y "trampa". De un modo general, dichos conceptos aparecen en aquellas ficciones en las que impera una necesidad de habilitación (finalmente siempre fallida) de un afuera.

«L'écriture télergique » est une analyse des premiers ouvrages de Levrero à partir du concept de « télergie » qui apparaît dans le Manuel de parapsychologie (1979). Dans nos travaux précédents, nous avons avancé que la fiction tardive de Levrero essaie d'accomplir une fonction de « mancie » (un concept aussi inclus dans le Manuel) pour atteindre un rapprochement à un Idéal du Moi insaisissable et à diverses formes de l'Absolu. Ici nous proposons que dans les premiers textes de l'auteur uruguayen la quête de l'identité idéale s'effectue à partir de la présentation de différents types de personnages, qui ne constituent que des versions incomplètes ou partielles du Moi du protagoniste. La télergie opère comme un concept qui explique, à partir de l'univers du Manuel, certaines inflexions singulières de ses premiers récits, tel le double. Par rapport au problème de l'identité, essentiel chez Levrero, nous analysons aussi d'autres concepts, tels que "toile d'araignée", "labyrinthe" et "piège", qui apparaissent dans ses fictions, marquées par un besoin d'aménager un dehors (toujours manqué).

"The telergic writing" proposes an analysis of Levrero's early work from the concept of "telergy" which appeared in his Manual of Parapsychology (Manual de Parapsicología, 1979). In previous essays it was stated that late levrerian fictions try to accomplish a "mancy" function (concept included in the Manual as well) to attain an approach to an ideal self as well as to different forms of the Absolute. Herein, it is proposed that in early texts from the Uruguayan author the search for an ideal identity is carried out through a presentation of different kinds of characters who are not but incomplete or partial versions of the protagonist-self. Telergy functions in this last sense as a concept that explains certain inflections of early levrerian narrative, like the double-type, from 
the universe of the Manual. Related to the identity problem, crucial in Levrero, other concepts present in his fictions such as the "cobweb", the "labyrinth" and the "trap" are also analyzed. In a general way, such concepts emerge from fictions that seek to overcome (but always fail) an outside.

ÍNDICE

Mots-clés: Mario Levrero, télergie, mancie, identité, Manuel de parapsychologie

Palabras claves: Mario Levrero, telergía, mancia, identidad, Manual de parapsicología

Keywords: Mario Levrero, telergy, mancy, identity, Manual of Parapsychology

AUTOR

LUCIANA MARTÍNEZ

UNR, CONICET 